\title{
Fats and oils adulteration: present scenario and rapid detection techniques
}

\author{
1, ${ }^{*}$ Huq, A.K.O., ${ }^{1}$ Uddin, I., ${ }^{2}$ Ahmed, E., ${ }^{1,3}$ Siddique, M.A.B., ${ }^{4}$ Zaher, M.A. and ${ }^{2}$ Nigar, S. \\ ${ }^{1}$ Department of Food Technology and Nutritional Science, Mawlana Bhashani Science and \\ Technology University, Tangail-1902, Bangladesh \\ ${ }^{2}$ Department of Nutrition and Food Technology, Jashore University of Science and Technology, \\ Jashore-7408, Bangladesh \\ ${ }^{3}$ Unicef Bangladesh, Dhaka-1000, Bangladesh \\ ${ }^{4}$ Institute of Nutrition and Food Science, University of Dhaka, Dhaka-1000, Bangladesh
}

\begin{abstract}
Article history:
Received: 18 February 2021

Received in revised form: 23 March 2021

Accepted: 29 May 2021

Available Online: 9 January 2022
\end{abstract}

Keywords:

Fats and oils,

Adulteration,

Rapid detection

\section{DOI:}

https://doi.org/10.26656/fr.2017.6(1).116

\begin{abstract}
Fats and oils are an essential part of everyday cooking as well as food products development and their purity are a concern since very early in human history. Adulteration of fats and oils is increased day by day throughout the world, a greater extent. Hence an attempt has been taken to review to identify different suitable rapid detection techniques for ensuring food quality and safety. The study was designed on the basis of extensive literature review for collecting relevant scientific evidence from various sources like Google Scholar, PubMed/Medline database, Science direct database, published journal, newspaper and periodicals. Various techniques have been utilized to assess the purity of edible fats and oils but yet they are costly and time-consuming. This study summarized the rapid detection techniques so that a common person can perform at the level of the household so as to have a broad picture of the status of adulteration in his food in case of doubt. Edible fats and oils are reported to be adulterated with other low-price oils. For example, mustard oil adulterated with argemone oil and butter yellow and ghee adulterated with vanaspati ghee. The leading challenges include the lack of market survey, lack of acceptance in the wholesale and retail market because of suspecting its purity, community health problem and decrease in consumer confidence.
\end{abstract}

\section{Introduction}

Edible oils and fats are essential nutritional requirements for humans and support the daily routine diet (Pitts et al., 2007). But it's a matter of regret that, because of their greater demand in national and international market adulteration in high price oil with low price oil is a major issue (Yadav, 2018). Adulteration is not observed due to its small-scale use and its low impact but it is present in society for a long time. The main cause for adulteration is treachery, increasing their income by enhancing its volume and shortage of accidental quality assessment on suspected products. Also, adulteration is conducted by some selfish businesses by enhancing their margin of profit (Ayza and Yilma, 2014). As the world population is growing at an alarming rate, food is often adulterated to meet the needs of this growing population and to feed the large-scale population. Food adulteration is spread at a higher rate in most developed countries in the world. Among them, for the last two decades, it turns into a very serious problem and causes serious threats of health risk of almost all populations (Majed et al., 2016).

It was obvious from the past incidents of oil adulteration; palm stearin and olein (fractions of palm oil) have been mixed together or with palm oil to give a product of unknown and variable quality. Animal fats and hydrogenated oils are often mixed with Ghee to adulterate it. Synthetic flavours and colours are added to other fats in order to make their appearance as ghee (Choudhary et al., 2020). Cheaper oil which is adulterated may also be characterized as if it were some oils of greater (pure) oil quality (Ebong et al., 2014). Historically, detecting such deceit has been problematic because of the small database establishing appropriate purity criteria for authentic edible oils and fats. In several cases, it has been observed that castor oil, karanja oil, mineral oil, and artificial colours are profoundly used to adulterate edible oils (Navya et al., 2017), edible 
soybean oil adulterated with linseed oil (Manandhar et al., 1986) and virgin olive oil adulterated with cotton oil and sunflower oils (Kesen, 2019) and vegetable oil.

At present fats and oils adulteration has been a significant problem worldwide, and it is necessary to establish rapid detection methods (Kou et al., 2018). It is very confusing for the consumers to select one food item because of deceptive advertisements, inappropriate media emphasis and food adulteration. As a result of these misconducts, the end-user gets victimized and subsequently suffers (Gupta and Panchal, 2009). Various procedures have been applied to assess the purity of edible oils and fats. In this study, a short review on edible fats and oils adulteration and their quick detection methods have been categorized. In order to find out adulterants from edible fats and oils different rapid and qualitative methods are being reported (Shukla and Dixit, 2005). Food organizations need to develop and adopt dependable techniques to sort out such impurities making markets and end-users more confident on the safety and purity of edible oils and fats.

The present study focuses on the rapid detection techniques for the identification of adulterated fats and oils. Also, this study expanded the horizon of knowledge regarding common food adulterants and to identify different types of food adulterants existing in various foodstuffs especially fats and oils.

\section{Methodology}

The extensive literature review was conducted for collecting relevant scientific evidence from various sources like Google Scholar, PubMed/ Medline database, Science direct database etc. using the keywords 'adulteration practice', 'detection technique of fats and oils' and 'adulteration scenario'. From the huge set of collected evidence, only those related to our concerned topic was screened for this brief narrative review.

\section{Current scenario of fats and oils adulteration}

It is seen that both branded and open edible oil selling within the markets and elsewhere are precariously polluted now. It was observed that about $31.25 \%$ of the packaged samples and $39.28 \%$ of the unpackaged samples were adulterated (Pal and Jain, 2018). The acts of pollution materialize at different platforms and phases of the production process right from the sector level right down to the consumers' end (Kamol, 2019). The research team has established adulteration in the samples of palm oil produced by Meizan and several other unbranded companies (Kamol, 2019). The mustard oil manufactured by Rupchanda, Radhuni, Teer, Fresh, Pushti, Shuresh, Danish and Boshudha have been found to be adulterated because the moisture contents within the samples they have tested were found higher than the Bangladesh Standard Testing Institute (BSTI) limit of 0.25 per cent (Kamol, 2019). Other adulteration signs such as the saponification value, the peroxide value and the relative density value in many of these samples do not meet the standard, researchers disclosed (Kamol, 2019). Adulteration of food may be stated as reducing the purity of the food by replacement (intentional or unintentional) with some lower quality external element or by removal of some value-added food substitute from main food. The present scenario concerning the hygiene and safety standard of all foods markedly provide us with the shocking situation of adulteration globally.

\section{Results and discussion}

Foods are being adulterated by using various harmful chemicals and poisonous synthetic colours (Derek, 2013). It is easy to contaminate fats and oils among other food items. But from nutritional significance, their purity is a concern since very early in human history. Due to their higher demand in the market (both national as well as international) mixing of high price oil with cheap oil is a foremost concern (Yadav, 2018). Edible fats and oils are adulterated by mixing cold press oil with refined oil and also by replacing expensive fats and oils with cheaper ones. The replacement of more costly oil by lesser one is so profitable for related businesses and hence they get inspired to do that (Siger et al., 2008) but detecting such adulterations are challenging. Common adulteration of mustard oil with butter yellow and argemone oil (Das and Khanna, 1997; Yadav, 2018) and also adulterated with cottonseed oil, mineral oil and castor oil (Navya et al., 2017) was shown in Table 1. It was also observed from Table 1 that cold press oil is costlier than refined oil; hence, businesses get lured to admix them and thus refined oils are used to adulterate cold press oil (Azadmard-Damirchi and Torbati, 2015). It has also been found that synthetic colours, castor oil, karanja oil, and mineral oil are profoundly used in adulterations of edible oil (Navya et al., 2017). Adulteration of pure cow and buffalo ghee with palm oil, soybean oil, vegetable oil, animal body fat, buffalo depot fat (Kumar et al., 2013; Gandhi et al., 2014), mixtures of oils and fats in cow milk fat (Kumar et al., 2010; Azadmard-Damirchi and Torbati, 2015).

Some vegetable oils and fats (VOFs) have a great value which is alluring for defrauders and hence they adulterate them with lower grade less expensive fats and oils to get more profit. Adulteration of vegetable oil is a universal problem irrespective of area or country. Another case is mustard oil adulteration with noxious argemone oil (de la Paz et al., 1996; Clemente and 
Table 1. Different types of fats and oils and their adulterants

\begin{tabular}{|c|c|c|}
\hline Fats and oils & Adulterants & References \\
\hline \multirow{6}{*}{$\begin{array}{l}\text { Mustard oil/Edible } \\
\text { oil }\end{array}$} & Argemone oil, papaya seed & Das and Khanna (1997) \\
\hline & Argemone oil (poisonous) & Clemente and Cahoon \\
\hline & & (2009); de la Paz et al. \\
\hline & Palm oil and others vegetables oil & \multirow{2}{*}{ Navya et al. (2017) } \\
\hline & Argemone oil, mineral oil, castor oil, prohibited color and dyes in fat & \\
\hline & Argemone oil and butter yellow & Yadav (2018) \\
\hline \multirow{4}{*}{ Virgin olive oil } & fatty acids and sterols of similar composition & $\begin{array}{l}\text { Azadmard-Damirchi and } \\
\text { Torbati (2015) }\end{array}$ \\
\hline & Adulterated with vegetables oil like peanut oil, soybean oil, mustard oil, & \multirow{2}{*}{ Christopoulou et al. (2004) } \\
\hline & Hazelnut oil & \\
\hline & Vegetable oil & Johnson (2014) \\
\hline \multirow{3}{*}{ Sunflower oil } & castor oil , palm oil and Paraffin & \multirow[b]{3}{*}{ Abhirami and Radha (2015) } \\
\hline & Argemone oil, mineral oil, castor oil & \\
\hline & Cottonseed oil and rapeseed oil & \\
\hline Loose edible oil & Palm oil or other cheap oils, castor oil, artificial colours and karanja oil & Navya et al. (2017) \\
\hline Cold press oil & Refined oils & $\begin{array}{l}\text { Azadmard-Damirchi and } \\
\text { Torbati }(2015)\end{array}$ \\
\hline \multirow{2}{*}{ Butter } & Vegetable oil, anatta, banana, oleomargarine & \multirow{2}{*}{ Safety and Road (2012) } \\
\hline & Mashed potato, sweet potato & \\
\hline \multirow[b]{2}{*}{ Cocoa butter } & Non-cocoa fat, Cocoa butter replacers/substitute & \multirow{2}{*}{$\begin{array}{l}\text { Buchgraber et al. (2007); } \\
\text { Ulberth and Buchgraber } \\
(2003)\end{array}$} \\
\hline & & \\
\hline \multirow{6}{*}{ Ghee } & Vanaspati, anatta, and oleomargarine, hydrogenated oils, animal fats and & \multirow{2}{*}{ Ayza and Belete (2015) } \\
\hline & Animal fat or palm oil & \\
\hline & Coal tar & Majed et al. (2016) \\
\hline & $\begin{array}{l}\text { Vanaspati/margarine, starches and mashed potatoes, rancid stuff, coloring } \\
\text { matter and coalter dye }\end{array}$ & Navya et al. (2017) \\
\hline & Vanaspati, paraffin and smashed potato & \\
\hline & Goat body fat & $\begin{array}{l}\text { Kumar et al. }(2010) \text {; Upadh- } \\
\text { yay et al. }(2016)\end{array}$ \\
\hline \multirow{6}{*}{$\begin{array}{l}\text { Cow and buffalo } \\
\text { ghee }\end{array}$} & Palm olein and sheep body fat & \multirow{4}{*}{ Gandhi et al. (2014) } \\
\hline & Vegetable oil & \\
\hline & animal fats and vegetable fats/oils & \\
\hline & Animal body fat & \\
\hline & Soyabean oil & Kumar et al. (2013) \\
\hline & Vegetable oil, Buffalo depot fat & Gandhi et al. (2014) \\
\hline Milk fat & Foreign fats/oils & $\begin{array}{lr}\text { Kumar et al. } & (2010 ; \\
\text { Azadmard-Damirchi } & \text { and } \\
\text { Torbati (2015) } & \\
\end{array}$ \\
\hline
\end{tabular}

Cahoon, 2009)(Table 1). Among VOFs, some have a specific element that might be absent in another one. For example, (E)-5-methylhept-2-en-4-one (filbertone) is recognized as a flavouring constituent of hazelnuts which is present in moderate amounts in the oil of hazelnut (Fox et al., 1988; Ruiz del Castillo et al., 1998; Ntakatsane et al., 2013). Brassica sterol is mainly found in canola oil and sesamolin, sesamon or sesamol are present entirely in sesame oil (Azadmard-Damirchi and Torbati, 2015). Ghee provides many amazing health benefits but it's a matter of regret that it is adulterated with vanaspati, hydrogenated oils, animal fats, synthetic colours, and coal tar (Ayza and Belete, 2015), also adulterated with paraffin and smashed potato (Navya et al., 2017). The overall adulteration summary of different fats and oils are given below with their possible adulterants (Table 1).
Today, adulterations are greater state-of-the-art. Therefore, it's far vital to apply superior and appropriate techniques to come across adulteration. Even though sophisticated laboratory protocols are reliable, precise and accurate but still they are expensive to conduct and also requires much time to operate. Hence it is useful to develop feasible and reliable "quick detection techniques" which a nontechnical individual can carry out at the household level which will have a vast photograph of repute of adulteration in his foods in time of uncertainty. For the detection of adulterated mustard oil, about $3 \mathrm{~mL}$ of mustard was placed in a test tube. Then $2 \mathrm{~mL}$ of amyl alcohol, $1 \mathrm{~mL}$ of carbon disulphide and a little amount of sulphur were placed in the test tube. After plugging the mouth of the test tube, heated it and observed a red coloration that indicates the presence of cottonseed oil in 
mustard oil (Azadmard-Damirchi and Torbati, 2015) (Table 2). It was also shown from Table 2 a separate colour layer was found when $5 \mathrm{~mL}$ of edible oils gently shaking with $5 \mathrm{~mL}$ of concentrated HCL, indicating the presence of prohibited colour in edible oils (FSSAI, 2012). The presence of cyanide in coconut oil was detected by adding 10 drops of alcoholic potash in $3 \mathrm{~mL}$ samples containing a test tube. Heated the test tube, and added addition of a little amount of each of the ferrous sulphate and ferric chloride in the test tube. After mixing properly $3 \mathrm{~mL}$ hydrochloric acid was added to it. The blue coloration indicates the presence of hydro cyanide acid due to the presence of cyanide in coconut oil
(FSSAI, 2012). The other sample of oil will get solidified after refrigerating leaving a separate layer of adulterant (FSSAI, 2012). By observing an orange colour of 5-phenylazo- $\gamma$-oryzanol or 5-phenylazoferulic acid when sample oil is treated with benzene diazonium chloride solution at $0-5^{\circ} \mathrm{C}$, denotes the presence of adulterants in rice bran oil (Shukla et al., 2004). The presence of mashed potatoes and sweet potatoes in a sample of ghee can easily be detected by adding a few drops of Iodine, which is brownish in colour turns to blue if mashed potatoes/sweet potatoes/other starches are present (FSSAI, 2012). The appearance of crimson colour in lower (acid) of vanaspati or margarine when

Table 2. Rapid detection techniques of fats and oils adulterations

\begin{tabular}{|c|c|c|c|}
\hline Food Article & Adulterants & Detection ways of adulteration & References \\
\hline \multirow{3}{*}{ Mustard oil } & Super soybean oil & By detecting separate colors with the help of a HCL-based kit. & Supriya (2020) \\
\hline & Cotton seed oil & By observing a red coloration after heating with amyl alcohol. & FSSAI (2012) \\
\hline & Argemone Oil & By seeing a red color after adding nitric acid in the sample. & $\begin{array}{c}\text { Abhirami and Radha } \\
\text { (2015) }\end{array}$ \\
\hline Soybean oil & Palm oil & $\begin{array}{l}\text { Separate layer of color will be observed after gentle shake in a } \\
\text { nitric acid based kit. }\end{array}$ & FSSAI (2012) \\
\hline \multirow{2}{*}{ Edible oil } & Prohibited color & $\begin{array}{l}\text { A layer of color will be observed after adding and shaking the } \\
\text { sample with HCL. }\end{array}$ & \multirow[t]{2}{*}{ FSSAI (2012) } \\
\hline & Rancidity & $\begin{array}{l}\text { The appearance of white color turbidity with the help of } \\
\text { ammonium molybdate reagent }\end{array}$ & \\
\hline \multirow{2}{*}{ Coconut oil } & Any oil & $\begin{array}{l}\text { Sample of oil will get solidified after refrigerating leaving a } \\
\text { separate layer of adulterant. }\end{array}$ & \multirow[t]{2}{*}{ FSSAI (2012) } \\
\hline & Cyanide & $\begin{array}{l}\text { Presence of blue color in the sample after addition of alcoholic } \\
\text { potash, ferrus sulphate and ferric chloride consecutively. }\end{array}$ & \\
\hline Olive oil & Vegetable oil & $\begin{array}{l}\text { Detected by conventional methods at below } 5 \% \text { adulteration } \\
\text { level }\end{array}$ & $\begin{array}{l}\text { Christopoulou et al. } \\
\qquad \text { (2004) }\end{array}$ \\
\hline Rice bran oil & Any other oil & $\begin{array}{l}\text { By observing an orange color of 5-phenylazo- } \gamma \text {-oryzanol or 5- } \\
\text { phenylazoferulic acid when sample oil is treated with } \\
\text { benzenediazonium chloride solution at } 0-5^{\circ} \mathrm{C}\end{array}$ & $\begin{array}{c}\text { Ulberth and } \\
\text { Buchgraber (2003) }\end{array}$ \\
\hline \multirow{4}{*}{$\begin{array}{l}\text { Sunflower } \\
\text { oil }\end{array}$} & $\begin{array}{l}\text { Palm oil, castor } \\
\text { oil and Paraffin }\end{array}$ & Using colorimeter & \multirow[t]{2}{*}{$\begin{array}{l}\text { Abhirami and Radha } \\
\text { (2015) }\end{array}$} \\
\hline & Castor Oil & $\begin{array}{l}\text { By the addition of } 10 \mathrm{~mL} \text { petroleum to the sample oil and } \\
\text { observing the white turbidity. }\end{array}$ & \\
\hline & Argemone oil & $\begin{array}{l}\text { A layer of red-brown color will indicate adulteration with } \\
\text { argemone oil when mixed with nitric acid. }\end{array}$ & FSSAI, 2012) \\
\hline & Mineral oil & $\begin{array}{l}\text { Heating with alcoholic potash and the presence of turbidity will } \\
\text { indicate adulteration with mineral oil. }\end{array}$ & FSSAI, 2012) \\
\hline \multirow{4}{*}{ Ghee } & Super palm oil & $\begin{array}{l}\text { By observing a color layer using a DPPH (2, 2-diphenyl -1- } \\
\text { picrylhydrazyl) -based kit. }\end{array}$ & \\
\hline & $\begin{array}{l}\text { Rancid stuff (old } \\
\text { ghee) }\end{array}$ & $\begin{array}{l}\text { By seeing a pink-red color layer at the bottom after the addition } \\
\text { of HCL and an ether solution }\end{array}$ & \multirow{3}{*}{ FSSAI (2012) } \\
\hline & $\begin{array}{l}\text { Synthetic coloring } \\
\text { matter }\end{array}$ & $\begin{array}{l}\text { The appearance of pink color or yellow color in acidic or alkaline } \\
\text { solution will indicate coloring matter. }\end{array}$ & \\
\hline & Vanaspati & $\begin{array}{l}\text { The presence of vanaspati will be detected by shaking the sample } \\
\text { with furfural solution. }\end{array}$ & \\
\hline \multirow[t]{2}{*}{ Ghee/ Butter } & $\begin{array}{l}\text { Mashed potatoes, } \\
\text { sweet potatoes } \\
\text { and other starches }\end{array}$ & $\begin{array}{l}\text { Can be detected easily by adding two drops of iodine and } \\
\text { consequently observing a blue color. }\end{array}$ & \multirow[t]{2}{*}{ FSSAI (2012) } \\
\hline & $\begin{array}{l}\text { Vanaspati/ } \\
\text { margarine }\end{array}$ & By adding HCL and observing a crimson color layer. & \\
\hline \multirow{3}{*}{$\begin{array}{l}\text { Vegetable } \\
\text { oil/Gingerly } \\
\quad \text { oil }\end{array}$} & Castor oil & $\begin{array}{l}\text { Formulation of turbidity might be observed after adding } \\
\text { ammonium molybdate reagent }\end{array}$ & \\
\hline & Argemone oil & $\begin{array}{l}\text { Yellow, orange or crimson color layer will indicate adulteration } \\
\text { after adding HNO3 }\end{array}$ & \multirow{2}{*}{$\begin{array}{l}\text { Abhirami and Radha } \\
\qquad(2015)\end{array}$} \\
\hline & Mineral oil & $\begin{array}{l}\text { The appearance of turbidity after addition of alcoholic potash and } \\
10 \mathrm{~mL} \text { of water. }\end{array}$ & \\
\hline
\end{tabular}


one teaspoon full of the melted sample of ghee with equal quantity of concentrated HCL acid and a pinch of sugar in a stoppered test tube (FSSAI, 2012). The appearance of turbidity indicates the presence of mineral oil when $2 \mathrm{~mL}$ of alcoholic potash and $10 \mathrm{~mL}$ of water are added to $2 \mathrm{~mL}$ of oil sample (Abhirami and Radha, 2015), white turbidity might be observed after adding a few drops of ammonium molybdate reagent in the mixture of $1 \mathrm{~mL}$ of the oil and $10 \mathrm{~mL}$ of acidified petroleum ether (FSSAI, 2012). A study reported a test for detection of neem oil $(0.5 \%)$ in others oil by observing the change in colour on heating at $200^{\circ} \mathrm{C}$ with the help of thin copper strip (Ramachandraiah et al., 1974). Another study observed colour reactions of vegetable oils with Carr-Price reagent (A chloroform solution of antimony trichloride) (Provedi, 1936). The summary of rapid detection techniques of fats and oils adulterations pointed in Table 2 .

\section{Conclusion}

Various edible fats and oils such as mustard oil, olive oil, sunflower oil, ghee, butter and cocoa butter were commonly adulterated by the inferior seeds oil and low-price vegetable oils. In this current situation, some acid-based or alkali-based colour changing rapid detection kits were developed for the identification of fats and oils adulteration rapid and quickly in the market areas. To get purity of edible oils and fats, consumers should be aware of those adulteration processes and the law enforcement agencies should be more observant for proper implementation of the law.

\section{Conflict of interest}

The authors declare no conflict of interest.

\section{References}

Abhirami, S. and Radha, R. (2015). Detection of food adulteration in selected food items procured by homemaker. International Journal of Recent Scientific Research, 6(8), 5938-5943.

Ayza, A. and Belete, E. (2015). Food adulteration: its challenges and impacts. Food Science Quality Management, 41, 50-56.

Ayza, A. and Yilma, Z. (2014). Patterns of milk and milk products adulteration in Boditti town and its surrounding, South Ethiopia. Journal of Agricultural Science, 4(10), 512-516.

Azadmard-Damirchi, S. and Torbati, M. (2015). Adulterations in some edible oils and fats and their detection methods. Journal of Food Quality and Hazards Control, 2(2), 38-44.

Buchgraber, M., Androni, S. and Anklam, E. (2007).
Determination of cocoa butter equivalents in milk chocolate by triacylglycerol profiling. Journal of Agricultural and Food Chemistry, 55(9), 3284-3291. https://doi.org/10.1021/jf063350z

Choudhary, A., Gupta, N., Hameed, F. and Choton, S. (2020). An overview of food adulteration: Concept, sources, impact, challenges and detection. International Journal of Chemical Studies, 8(1), 2564-2573.

chemi.2020.v8.i1am.8655

Christopoulou, E., Lazaraki, M., Komaitis, M. and Kaselimis, K. (2004). Effectiveness of determinations of fatty acids and triglycerides for the detection of adulteration of olive oils with vegetable oils. Food Chemistry, 84(3), 463-474. https:// doi.org/10.1016/S0308-8146(03)00273-5

Clemente, T.E. and Cahoon, E.B. (2009). Soybean oil: genetic approaches for modification of functionality and total content. Plant Physiology, 151(3), 10301040. https://doi.org/10.1104/pp.109.146282

Das, M. and Khanna, S.K. (1997). Clinicoepidemiological, toxicological, and safety evaluation studies on argemone oil. Critical Reviews in Toxicology, 27(3), 273-297. https:// doi.org/10.3109/10408449709089896

de la Paz, M.P., Philen, R.M., Borda, I.A., Socias, J.S., de la Cámara, A.G. and Kilbourne, E.M. (1996). Toxic oil syndrome: Traceback of the toxic, oil and evidence for a point source epidemic. Food and Chemical Toxicology, 34(3), 251-257. https:// doi.org/10.1016/0278-6915(95)00111-5

Derek, L. (2015). Eight toxic foods: a little chemical education. Retreived from Science website: https:// www.science.org/content/blog-post/eight-toxicfoods-little-chemical-education

Ebong, S.T., Akpabio, G.T., Attai, E.S. and Oji, H.E. (2014). Adulteration detection in some edible oil products in Nigeria. International Journal of Research Studies in Science, Engineering and Technology, 1(4), 68-72.

FSSAI (Food Safety and Standard Authority of India). (2012). Quick Test for Some Adulterants in Food. Retreived from FSSAI website: https:// old.fssai.gov.in/Portals/0/Pdf/

Final_Test_kit_Manual_II(16-08-2012).pdf

Fox, J.R., Duthie, A.H. and Wulff, S. (1988). Precision and sensitivity of a test for vegetable fat adulteration of milk fat. Journal of Dairy Science, 71(3), 574581. https://doi.org/10.3168/jds.S0022-0302(88) 79593-4

Gandhi, K., Upadhyay, N., Aghav, D., Sharma, V. and Lal, D. (2014). Detection of adulteration of ghee 
(clarified milk fat) with palmolein and sheep body fat using Reichert-Meissl (RM) value coupled with solvent fractionation technique. Indian Journal of Dairy Science, 67(5), 387-393.

Gupta, N. and Panchal, P. (2009). Extent of awareness and food adulteration detection in selected food items purchased by home makers. Pakistan Journal of Nutrition, 8(5), 660-667. https://doi.org/10.3923/ pjn.2009.660.667

Johnson, R. (2014). Food fraud and "Economically motivated adulteration" of food and food ingredients. Retreived from website: https://sgp.fas.org/crs/misc/ R43358.pdf

Kamol, E. (2019). DU finds milk, edible oils, spices adulterated. New Age Bangladesh. Retrieved from https://www.newagebd.net/article/76499/du-findsmilk-edible-oils-spices-adulterated

Kesen, S. (2019). Monitoring Fatty Acid and Sterol Profile of Nizip Yaglik Olive Oil Adulterated by Cotton and Sunflower Oil. Journal of Oleo Science, 68(9), 817-826. https://doi.org/10.5650/ jos.ess 19130

Kou, Y., Li, Q., Liu, X., Zhang, R. and Yu, X. (2018). Efficient detection of edible oils adulterated with used frying oils through PE-film-based FTIR spectroscopy combined with DA and PLS. Journal of Oleo Science, 67(9), 1083-1089. https:// doi.org/10.5650/jos.ess18029

Kumar, A., Lal, D., Seth, R. and Sharma, V. (2010). Detection of milk fat adulteration with admixture of foreign oils and fats using a fractionation technique and the apparent solidification time test. International Journal of Dairy Technology, 63 (3), 457-462. https://doi.org/10.1111/j.14710307.2010.00562.x

Kumar, A., Neelam Upadhyay, K.G., Lal, D. and Sharma, V. (2013). Detection of soybean oil and buffalo depot fat in ghee using normal-phase thin layer chromatography. Indian Journal of Dairy Science, 66(4), 288 - 293.

Majed, N., Real, M., Isreq, H., Akter, M. and Azam, H.M. (2016). Food adulteration and biomagnification of environmental contaminants: a comprehensive risk framework for Bangladesh. Frontiers in Environmental Science, 4, 34. https://doi.org/10.3389/fenvs.2016.00034

Manandhar, P.P., Nagao, A. and Yamazaki, M. (1986). Determination of content of linseed oil in edible soybean oil. Journal of Japan Oil Chemists' Society, 35(9), 725-730. https://doi.org/10.5650/ jos 1956.35 .725

Navya, P., Raju, K. and Sukumaran, M.K. (2017).
Analysis of food adulterants in selected food items purchased from local grocery stores. International Journal of Advances in Scientific Research, 3(7), 8289. https://doi.org/10.7439/ijasr.v3i7.4299

Ntakatsane, M.P., Liu, X.M. and Zhou, P. (2013). Rapid detection of milk fat adulteration with vegetable oil by fluorescence spectroscopy. Journal of Dairy Science, 96(4), 2130-2136. https://doi.org/10.3168/ jds.2012-6417

Pal, A.D. and Jain, A. (2018). Adulteration in Commonly Used Cooking Oils of Kolkata: Evaluation of Consumer Perception and Detection of Adulterants. International Journal of Health Sciences and Research, 8(12), 30-37.

Pitts, M., Dorling, D. and Pattie, C. (2007). Oil for food: the global story of edible lipids. Journal of WorldSystems Research, 13(1), 12-32. https:// doi.org/10.5195/jwsr.2007.358

Provedi, F. (1936). Color reactions of vegetables oil. Oil Minerali, Olliigrassi, Coroli vereci, 16, 103-104.

Ramachandraiah, O.S., Thirumalarao, S.D. and Reddy, B.R. (1974). Detection of Neem Oil. Journal of the Oil Technologists' Association of India, 6, 50.

Ruiz del Castillo, M.L., Caja, M.D.M., Herraiz, M. and Blanch, G.P. (1998). Rapid recognition of olive oil adulterated with hazelnut oil by direct analysis of the enantiomeric composition of filbertone. Journal of Agricultural and Food Chemistry, 46(12), 51285131. https://doi.org/10.1021/jf9807014

Shukla, A.K., Dixit, A.K. and Singh, R.P. (2005). Detection of adulteration in edible oils. Journal of Oleo Science, 54(6), 317-324. https:// doi.org/10.5650/jos.54.317

Shukla, A.K., Johar, S.S., Dixit, A.K. and Singh, R.P. (2004). Identification of Physically Refined Rice Bran Oil and Its Simple Detection in Other Oils. Journal of Oleo Science, 53(8), 413-415. https://doi.org/10.5650/jos.53.413

Siger, A., Nogala-kalucka, M. and Lampart-Szczapa, E. (2008). The content and antioxidant activity of phenolic compounds in cold-pressed plant oils. Journal of Food Lipids, 15(2), 137-149. https:// doi.org/10.1111/j.1745-4522.2007.00107.x

Supriya, K. (2020). Methods for Detection of common adulterants in food. Retrieved from Vikaspedia website: http://vikaspedia.in/health/healthcampaigns/beware-ofadulteration/methods-fordetection-of-commonadulterants-in-food.

Ulberth, F. and Buchgraber, M. (2003). Analytical platforms to assess the authenticity of cocoa butter. European Journal of Lipid Science and Technology, 105(1), 32-42. https://doi.org/10.1002/ 
ej1t.200390003

Upadhyay, N., Jaiswal, P. and Jha, S.N. (2016). Detection of goat body fat adulteration in pure ghee using ATR-FTIR spectroscopy coupled with chemometric strategy. Journal of Food Science and Technology, 53(10), 3752-3760. https:// doi.org/10.1007/s13197-016-2353-2

Yadav, S. (2018). Edible oil adulterations: Current issues, detection techniques, and health hazards. International Journal of Chemical Studies, 6(2), 1393-1397. 